
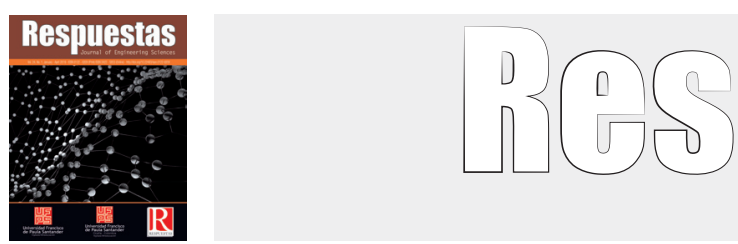
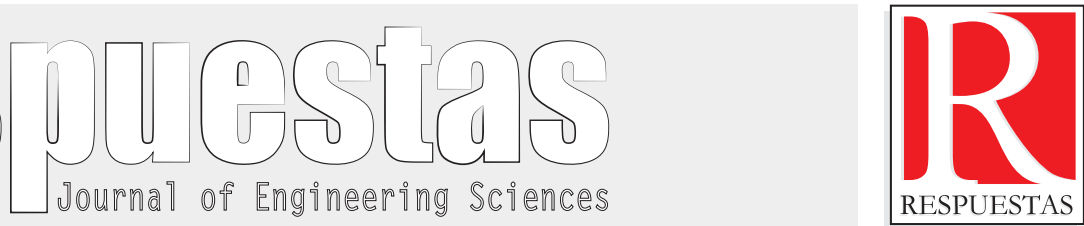

Original Article

https://doi.org/10.22463/0122820X.1795

\title{
Experimental prototype for visual support in the calibration of the precision indicator lights of approach slope, for a landing track using a drone
}

\author{
Prototipo experimental de soporte visual en la calibración de las luces indicadoras de precisión de la pendiente \\ de aproximación, para una pista de aterrizaje utilizando un avión teledirigido
}

\author{
Jorge Enrique Herrera-Rubio ${ }^{1 *}$, Sergio Andrés Parra-Prada ${ }^{2}$ \\ I*Doctor en ciencias, Jherrera@unipamplona.edu.co, ORCID: 0000-0002-9661-5450, Universidad de Pamplona, Cúcuta, Colombia. \\ 2Ingeniero en telecomunicaciones, Sapp514@gmail.com, ORCID: 0000-0002-9240-8892, Universidad de Pamplona, Cúcuta, Colombia.
}

How to cite: J. Herrera-Rubio y S. Parra-Prada, "Experimental prototype for visual support in the calibration of the precision indicator lights of approach slope, for a landing track using a drone”. Respuestas, vol. 24, no. 1, pp. 40-47, 2019.

Received on May 20, 2018; Approved on September 20, 2018

\section{ABSTRACT}

Keywords:

Aircraft

Visual aids

Calibration

Samples

Pending

The use of calibration methods for visual aids systems in airports guarantees aviation safety with new alternatives and precision methods. The article shows the implementation of an experimental prototype for the support of visual aid in the calibration of precision indicator lights by means of a drone to improve the approach slopes of aircraft. In each of the experimental tests the following activities were developed: a) execute the program that contains the code to perform the process of emulation / calibration of the lights, b) connect the model of the lights to the Arduino and be connected to the portable equipment, c) perform the drone calibration process each time a flight plan is made, d) connect the mobile device to the drone's remote control to integrate them into the wireless network (Wi-Fi), e) on the device mobile the application is executed to configure the flight plan and f) the emulation / calibration is performed with the model of the lights. Obtain the best visibility angles according to the effective percentages of experimentation that indicate the accuracy of the experimental system proposed through a mobile application. In addition, this article proposes a methodology for the calibration of the Precision Approach Path Indicator (PAPI) lights through wireless devices. The proposed methodology establishes the basic conditions for the development of the process of supervision, monitoring and calibration of the PAPI lighting system of any track in Colombia according to the regulations on luminous visual aids.

\section{RESUMEN}

\section{Palabras clave:}

Aviones

Ayudas visuales

Calibración

Muestras

Pendiente
El uso de métodos de calibración para los sistemas de ayudas visuales en los aeropuertos garantiza la seguridad aérea con nuevas alternativas y métodos de precisión. El artículo muestra la implementación de un prototipo experimental para el apoyo de la ayuda visual en la calibración de los indicadores luminosos de precisión mediante un avión teledirigido para mejorar las pendientes de aproximación de los aviones. En cada una de las pruebas experimentales se desarrollaron las siguientes actividades: a) ejecutar el programa que contiene el código para realizar el proceso de emulación/calibración de las luces, b) conectar el modelo de las luces al Arduino y estar conectado al equipo portátil, c) realizar el proceso de calibración del drone cada vez que se realiza un plan de vuelo, d) conectar el dispositivo móvil al mando a distancia del drone para integrarlo en la red inalámbrica (Wi-Fi), e) en el dispositivo móvil se ejecuta la aplicación para configurar el plan de vuelo y f) la emulación/calibración se lleva a cabo con el modelo de las luces. Obtener los mejores ángulos de visibilidad en función de los porcentajes efectivos de experimentación que indican la precisión del sistema experimental propuesto a través de una aplicación móvil. Además, este artículo propone una metodología para la calibración de las luces del Indicador de Trayectoria de Aproximación de Precisión (PAPI) a través de dispositivos inalámbricos. La metodología propuesta establece las condiciones básicas para el desarrollo del proceso de supervisión, monitoreo y calibración del sistema de iluminación PAPI de cualquier vía en Colombia de acuerdo con la normativa sobre ayudas visuales luminosas.

*Corresponding author.

E-mail address: Jherrera@unipamplona.edu.co (Jorge Enrique Herrera Rubio)

(c) $(1) \Theta$ Peer review is the responsibility of the Universidad Francisco de Paula Santander.

cc) This is an article under the license CC BY-ND (http://creativecommons.org/licenses/by-nc-nd/4.0/). 


\section{Introduction}

The calibration system of the precision approach trajectory indication lights in international airports, as in the case of Colombia, allows visual navigation aids to facilitate area operations more efficiently and safely, there are illuminated visual aids and not illuminated, the first ones refer to all the lights that are installed in the airports and the second ones refer to the marks that are made within the maneuvering area established in the aeronautical regulations [1].

The type of PAPI can be a system consisting of 4 units of lights or a system consisting of 2 units of light, which are located on one side of the track in a line perpendicular to the center line of the track to define the angle visual of the glide path [2], the lights are positioned to produce a visual presentation in which a pilot near the path of the established path can determine their relative position of the gliding triangle based on the colors of the lights as observed by the pilot at the time of landing.

Flight inspections that include the review and calibration of PAPI lights for airport navigation aids are carried out with light aircraft equipped with sensor systems and non-automated, slow and expensive calibration systems; [3] based on the foregoing and through the entry into force of Circular 002, issued by the Colombian Civil Aviation in 2015 on the use of drones in airspace, it has been proposed [4] to use as technological alternative the use of drones to perform a more autonomous, fast and accurate process of calibrating these lights. Similarly, the company Aena [5] has specialized in the use of drones equipped with sensors to provide a controlled, autonomous and unrepeatable flight with high precision measurements at airports to calibrate PAPI lights.

Normally when a pilot has started the descent route in the final segment of the instrument approach, and after starting the approach segment he receives the last meteorological report; the pilot can continue the approach to the decision height $(\mathrm{DH})$ or to the minimum descent height (MDA) [6], use at least the rows of the red bars that are clearly identified as a reference of the PAPI approach lights on the next elevation level of the runway.
Recently the Federal Aviation Administration (FAA) by means of a memorandum dated December 19, 2017 issues the updated engineering report (EB 95) that provides clarifications and additional guidance to airports, Airport District Offices (ADO) and architectural companies and engineering with respect to the updated PAPI flight inspection criteria defined by the FAA in Order 8200.ID; there, the evaluation of obstacles outside 10 degrees is clarified. The data collected by the FAA of the installed and operational PAPIs indicates that the horizontal light beam or the light signal propagation from a PAPI can be up to \pm 13 degrees from the center line of the runway, the FAA flight inspection now evaluates the full angular coverage of the PAPI light beam, beyond 10 degrees to Obstacle-Free Surface (OCS), a situation that is not addressed in the investigation because it is a new document that will be implemented in Colombian airports in a near future [7].

The new method of colorimetric measurement proposed by [8] for the transition width of the path of the precision approach path uses a spectrometer, a fiber probe, a moving medium and a ruler, using the spectrometer measuring the coordinates of Chromaticity to distinguish white and red light. The fiber probe is the spectrometer input and calculate the angle of the approach path. With the measuring distance of 10 meters and the precision of the 1 millimeter ruler, a system accuracy of 21 arc seconds is obtained.

For their part, [9] used an incandescent light source (Signal Light Gun) as an instrument used by air traffic controllers to communicate with pilots who are experiencing radio faults, the signal light gun test ( SLGT) allowed the practical evaluation so that the pilots can distinguish the incandescent lights between the colors: red, green and white; They determined the critical problems indicating that the color signaling lights: red and white allow to guide the approach route, this investigation provides a differentiation to the color vision for the pilots within the medical aero exams and the color chromaticity differentiation according to the FAA. 
In recent years, the concept of performancebased navigation (PBN) for manned aviation was introduced to exploit satellite navigation performance and manage available airspace, obviously transferring the PBN concept for drone applications, without However, since drones usually use commercial equipment that is generally not certified for aviation applications, the question is how can the basic principle be transferred to the PBN concept? Likewise, the research carried out by [10] where they propose the incorporation of drones into airspace as a key factor for the integration of geo-referenced systems in areas of air exclusion that allow airspace management for unmanned traffic.

\section{Materials and methods}

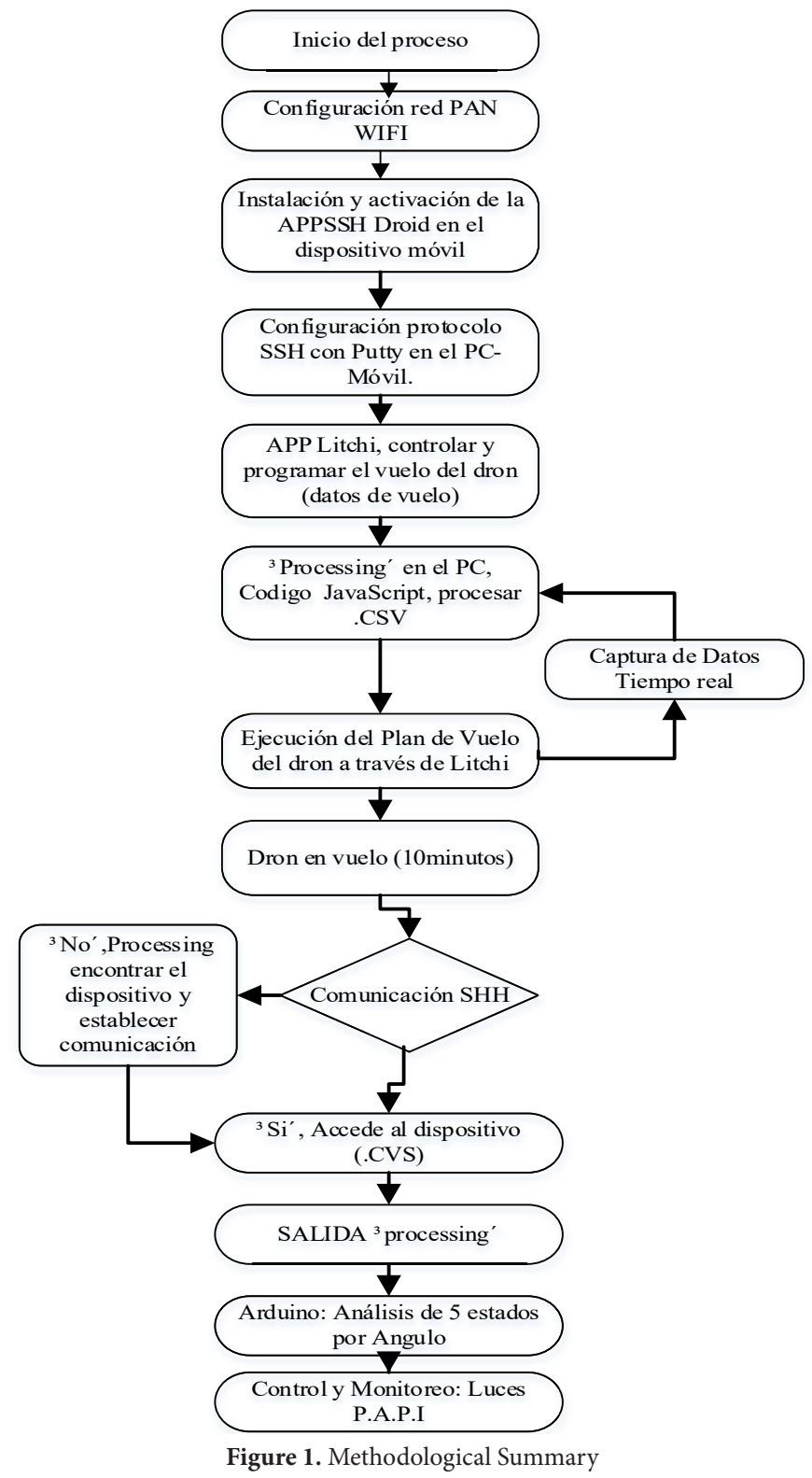

The research work was confined on a sports field in order to establish the parameters that affect the calibration of the approach indication precision approach system for a learning track by means of a drone, the methodology is described in Figure 1.

In each of the experimental tests the following activities were carried out: a) connect the model of the lights to the Arduino and be connected to the portable equipment, b) execute the "Processing" program that contains the code to perform the emulation / calibration process of the lights, c) perform the drone calibration process each time a flight plan is made, $d$ ) connect the mobile device to the drone's remote control to integrate them into the wireless (Wi-Fi) network, e) in the mobile device runs the Litchi application to configure the flight plan and start the capture of data that is stored in the internal memory of the cell phone and f) the emulation / calibration is carried out with the model of the lights.

\section{Measures Campaign}

Each of the tests is carried out with the drone "Phamton 3 - Standard", in a confined space, in this case on the soccer field of the Universidad Francisco de Paula Santander, a model was made to emulate the PAPI lights, as shown in figure 2:

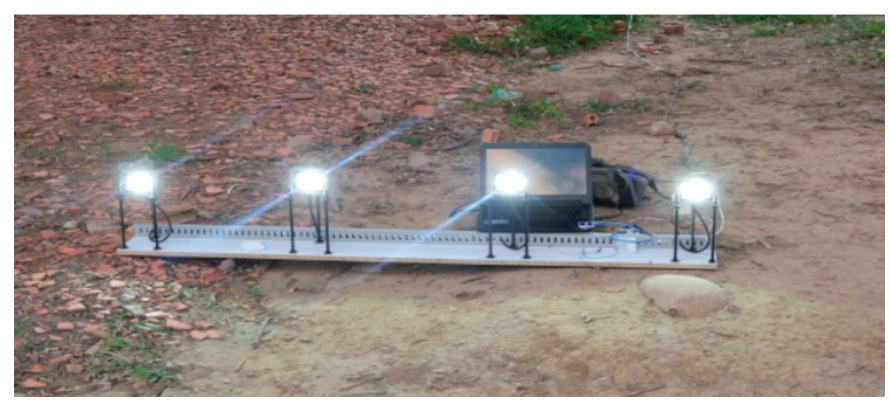

Figure 2. Emulator circuit precision approximation indicator lights

The model consists of four reflectors that have a visual range of up to 30 meters, work with 110 VAC voltage, raised on a support similar to that of the lights in the airport at an approximate height of 30 $\mathrm{cm}$ and that are connected to a relay respectively and are controlled with an Arduino board circuit [11] that sends the information depending on the location of the drone.

The field trip is done for 6 different days in the 
afternoon hours for approximately 10 minutes. To take the samples, the measurements are normalized depending on the approach angle (the angles from $2.4^{\circ}$ to $3.5^{\circ}$ are tabulated) that allows the distance of the mobile or drone to be found within the path or range of display; for this case, the angle between 2.9 and 3.1 is taken as an example; as seen in table I. to start capturing the data generated by the drone

\section{Connectivity tests}

The measurements are made on the route in the open field with the obtaining of data in text format in a file with extension .CSV through the Lichi application

Table I. Example of angle for location in the flight senda

\begin{tabular}{|c|c|c|c|c|c|c|c|}
\hline \multicolumn{8}{|c|}{ ANGLE $2.9^{\circ}-3.1^{\circ}($ IN THE PATH $)$} \\
\hline \multicolumn{4}{|c|}{ Airport - Plane } & \multicolumn{4}{|c|}{ Campus - Drone } \\
\hline $\begin{array}{c}\text { Hypotenuse } \\
\text { (m) }\end{array}$ & $\begin{array}{c}\text { Angle } \\
\text { (degrees) }\end{array}$ & Distance (m) & $\begin{array}{l}\text { Height } \\
\text { (m) }\end{array}$ & $\begin{array}{c}\text { Hypotenuse } \\
\text { drone (m) }\end{array}$ & $\begin{array}{c}\text { Drone } \\
\text { Distance } \\
\text { (m) }\end{array}$ & Angle & $\begin{array}{c}\text { Drone } \\
\text { Height } \\
\text { (y) }\end{array}$ \\
\hline 550 & 3,1 & 549,19516868 & 29,74 & 55 & 54,91951687 & 3,1 & 2,97 \\
\hline 800 & 3,1 & 798,82933626 & 43,26 & 80 & 79,88293363 & 3,1 & 4,33 \\
\hline 550 & 3 & 549,2462441 & 28,78 & 55 & 54,92462441 & 3 & 2,88 \\
\hline 800 & 3 & 798,9036278 & 41,87 & 80 & 79,89036278 & 3 & 4,19 \\
\hline 550 & 2,9 & 549,2956465 & 27,83 & 55 & 54,92956465 & 2,9 & 2,78 \\
\hline 800 & 2,9 & 798,9754857 & 40,47 & 80 & 79,89754857 & 2,9 & 4.05 \\
\hline
\end{tabular}

Here the comparison of the values of the international standard is observed when carrying out the tests with a plane as required by air regulation and the approximate normalization carried out with the drone; for which the reference angle is taken into account to find the distance at which the mobile phone should be located by varying its height, with equation (1):

$$
d=\cos \emptyset * h \quad \text { (1) }
$$

Using a linear approximation, you can find the height of the mobile as a function of distance, with equation (2):

$$
\text { Height }=0,05415806 * h+0,0435
$$

\section{Software Installation and Configuration}

The personal area network is configured through a wireless connection in the $2.4 \mathrm{GHz}$ frequency between the cell phone, the drone and the laptop that serves as a server, then the "APP SSH DROID" application is installed on the mobile device where the connection to the server will be made online, in the same way the PuTTy program is installed and configured using the SSH protocol based on the client-server concept that allows the remote and secure connection of the data flow control that will be sent from the mobile device and the server.

To control the flight, altitude, range, speed and direction, the Lychee APP is installed and executed where all the data of the flight that captures the drone is stored, this file addresses the information in the folder / LitchiAPP / Flightlogs.

Simultaneously, the "Processing" application is executed on the server computer that contains the code written in JavaScript for the reading, interpretation and processing of the CSV file mentioned above.

\section{Data collection}

The data is continuously recorded and generated in the drone through the Litchi application database, for estimated time between 8 and 10 minutes of flight, maintaining communication through the SSH protocol so that The Java Script APP finds and maintains the connection with the drone to access the device and process the .CSV file, as shown in table II.

\begin{tabular}{|c|c|c|c|}
\hline VARIABLE & DATA 1 & DATA 2 & DATA N \\
\hline Latitude & $7.900,063$ & $7.900,066$ & $7.900,068$ \\
\hline Longitude & $-72.487,668$ & $-72.487,673$ & $-72.487,677$ \\
\hline Altitude (foot) & 137 & 136 & 136 \\
\hline Altitude (m) & 41,7576 & 41,4528 & 41,4528 \\
\hline Ascent (foot) & 137 & 136 & 136 \\
\hline Speed $(\mathrm{mph})$ & 13.52 & 13.52 & 13.70 \\
\hline Distance (foot) & 351 & 349 & 348 \\
\hline Distance (m) & 106,9848 & 106,3752 & 106,0704 \\
\hline Angle & 23,0 & 22,9 & 23,0 \\
\hline P.A.P.I lights & very high & very high & very high \\
\hline Max_altitude (foot) & 179 & 179 & 179 \\
\hline Max_ascent (foot) & 179 & 179 & 179 \\
\hline Max_speed (mph) & 14.16 & 14.16 & 14.16 \\
\hline Max_distance (foot) & 464 & 464 & 464 \\
\hline Time (millisecond) & 147238 & 147287 & 147387 \\
\hline $\begin{array}{l}\text { Date time (yy-mm- } \\
\text { dd / hh: mm: ss) }\end{array}$ & $\begin{array}{c}2017-12-29 \\
16: 38: 33.742 \\
\end{array}$ & $\begin{array}{c}2017-12-29 \\
16: 38: 33.790\end{array}$ & $\begin{array}{c}2017-12-29 \\
16: 38: 33.890 \\
\end{array}$ \\
\hline
\end{tabular}

Table II. Example of data capture in .csv format from the dron 
In the case of study, consider a margin of error of $10 \%$, with a confidence level of $95 \%$ for a standardized standard distribution and work with 56199 samples, applying equation 3 .

$$
n=\frac{\left(N * Z^{2} * p * q\right)}{\left.d^{2} *(N-1)+Z^{2}(p * q)\right)}
$$

Where: $\mathrm{N}$ is the sample size, $\mathrm{Z}$ the level of confidence, $p$ the portion of expected success, $q$ probability of failure and $d$ is the maximum permissible error, therefore, it is essential that the design of experiments [12] should be Consider the determination of the sample size required to obtain the modification of the population parameters with a certain precision.

\section{Measurement (data selection)}

The data obtained are filtered and processed in order to determine the angle based on the number of samples, as shown in Table III.

\section{Measurement results}

Once the capture process is finished, the inclination angles are calculated according to the aeronautical norm, to find the closest value to the flight path, equations 1 and 2 are considered; with which the average distances and heights in the range between 550 meters and 880 meters are obtained, as shown in table IV.

It can be seen that in order to maintain the average values of the angles, the height of the drone is the referent to find said value, taking into account the line of sight with respect to the distance of the hypotenuse that is formed with respect to the horizon where the drone, allowing to guarantee an optimal path angle.

\section{Data conversion and presentation of results}

Finally, by means of the code executed by the

Table III. Consolidated capture during measurement days

\begin{tabular}{|c|c|c|c|c|c|c|}
\hline Day & 12-dic-17 & 16-dic-17 & 27-dic-17 & 23-dic-17 & 29-dic-17 & 26-ene-18 \\
\hline Hour & $15: 25$ & $17: 29$ & $17: 27$ & $17: 41$ & $16: 57$ & $15: 10$ \\
\hline Test time (min) & $2: 41$ & $18: 54$ & $12: 38$ & $16: 56$ & $21: 01$ & $12: 16$ \\
\hline Average sample (s) & 0,0999 & 0,2812 & 0,0434 & 0,0200 & 0,0999 & 0,1111 \\
\hline Correct data time & 91,9227131 & 762,643944 & 125,0388 & 330,9027 & 804,24834 & 505,7084 \\
\hline Null data time & 68,64228 & 374,9470 & 33,30312 & 81,2252 & 456,9706 & 236,6115 \\
\hline Correct data & 920 & 7477 & 3276 & 16540 & 8043 & 6964 \\
\hline Null data & 867 & 367 & 766 & 4060 & 4570 & 2349 \\
\hline Total data & 1787 & 7844 & 4042 & 20600 & 12613 & 9313 \\
\hline \multicolumn{7}{|c|}{ Determination of the angle (samples) } \\
\hline Very high: & 886 & 6050 & 1646 & 10895 & 4920 & 4365 \\
\hline High & 34 & 684 & 180 & 161 & 479 & 205 \\
\hline On the path & 0 & 705 & 220 & 140 & 531 & 222 \\
\hline Low & 0 & 38 & 309 & 340 & 578 & 306 \\
\hline Very low & 0 & 0 & 921 & 5004 & 1535 & 1865 \\
\hline Total samples & 920 & 7477 & 3276 & 16540 & 8043 & 6964 \\
\hline \multicolumn{7}{|c|}{ Time to calculate the angle } \\
\hline Very high time & 88,52556938 & 617,0918632 & 71,562584 & 217,9677 & 491,968404 & 195,37467 \\
\hline High time & 3,397143746 & 69,76708007 & 3,2210004 & 3,2210004 & 47,8969239 & 13,584731 \\
\hline Path time & 0 & 71,90905182 & 2,8008699 & 2,8008699 & 53,0965899 & 14,674582 \\
\hline Low time & 0 & 3,875948893 & 13,434288 & 6,8021126 & 57,7962881 & 19,508172 \\
\hline Very low time & 0 & 0 & 40,042005 & 100,11109 & 153,490142 & 73,41081 \\
\hline
\end{tabular}

Table IV. Average of the angle conditions within the tests

\begin{tabular}{|c|c|c|c|c|c|}
\hline VARIABLES & $\begin{array}{c}\text { ANGLE }<2.4 \\
{ }^{\circ} \text { (very low) }\end{array}$ & $\begin{array}{c}A N G L E 2.5^{\circ}- \\
2.8^{\circ} \text { (slightly } \\
\text { low) }\end{array}$ & $\begin{array}{c}A N G L E 2.9^{\circ} \\
3.1^{\circ}-(\text { on the } \\
\text { path) }\end{array}$ & $\begin{array}{c}\text { ANGLE } 3.2^{\circ} \text { - } \\
3.5^{\circ} \text { (slightly } \\
\text { high) }\end{array}$ & $\begin{array}{c}A N G L E> \\
3.5^{\circ}(\text { high })\end{array}$ \\
\hline Hypotenuse average (m) & 550 & 550 & 550 & 550 & 550 \\
\hline Average height (m) & 21,59 & 25,43 & 28,78 & 32,14 & 35,97 \\
\hline Distance (m) & 549,5760 & 549,4117 & 549,2463 & 549,06012 & 548,8225 \\
\hline Angle (m) & 2,2 & 2,5 & 3 & 3,4 & 3,7 \\
\hline Hypotenuse average (m) & 800 & 800 & 800 & 800 & 800 \\
\hline Average height $(\mathrm{m})$ & 31,405 & 36,99 & 41,8666 & 46,75 & 52,322 \\
\hline Distance $(\mathrm{m})$ & 799,3832 & 799,1443 & 798,9037 & 798,6328 & 798,2871 \\
\hline Angle (degrees) & 2,2 & 2,5 & 3 & 3,4 & 3,7 \\
\hline
\end{tabular}


Processing application [13] it is possible to discriminate the status of the PAPI lights for each line of sight angle with respect to the landing path, as shown in the example in Figure 3 with a part of the application code developed for the capture and processing of data obtained from the drone; With the rapid idealization of prototypes according to [14], practical research is possible where tools are used for debugging, searching and reusing code, specifically aimed at this style of application development in an agile and functional way.

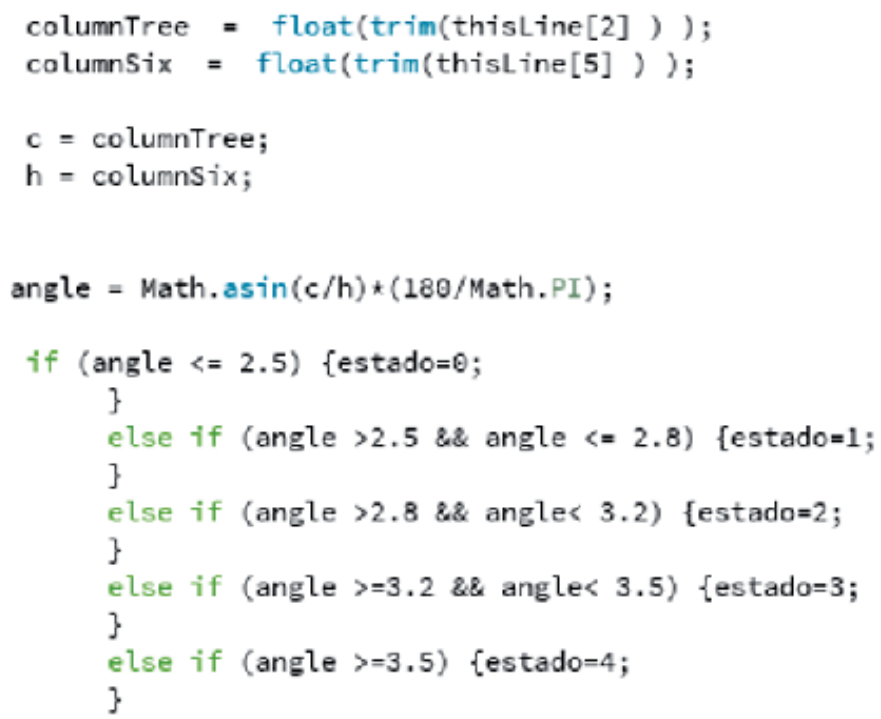

\section{Results and Discussion}

For each of the different tables, a comparison of the range of heights on a runway with the plane and in the test field with the drone is made. 5 tables were designed for each angle range with indications of: very low, low, on the path, high, very high.

For each angle a maximum point of 800 meters and a minimum of 550 meters were taken, which is the range of heights used in tests with an aircraft to indicate the position when standardizing the measurements in the test environment. Through mathematical calculations, the heights for each angle are found and at the end a general equation of the line for each interval is obtained depending on the position of the drone.

Table IV shows the best path that indicates to the drone that it is in a good position to calibrate the
Accuracy Approach Indicator Lights in the distance of 800 meters with respect to the diagonal of the lights that should be at a height of 41,87 meters and in the case of 550 meters should be 28.78 meters.

Analyzing the data in Table III, it is observed that the effective percentages of experimentation are taken as a reference of the total samples per day and are related to the correct data samples, which correspond to: $51.2 \%, 95.3 \%, 81.05 \%, 80.3 \%, 60.8 \%$ and $74.8 \%$ during the 6 days respectively; this allows to demonstrate that on the first day it was not possible to determine the angle, on day two with 705 samples the precision angle on the path represented $9.4 \%$ of the total of the correct samples, which indicates that, the remaining value of 6772 are analyzed by the mathematical algorithm to determine the angle in either very high, high, low and very low.

Based on the above, for this particular day with an accuracy of $95.3 \%$ of the data in a time of 71.9 seconds it is possible to locate the drone on the path. In the same way, the analysis can be carried out for the other days, considering the percentage of the correct data.

\section{Conclusions}

A process of supervision, monitoring and calibration of the PAPI lighting system of any runway in Colombia requires security protocols through the standardization of procedures, equipment regulations and infrastructures related to air traffic in force on light visual aids as is the case of: FAA Airport Safety and Standards (engineering brief NO. 95) and RC4 Airworthiness and aircraft operation standards of the Special Administrative Unit of Colombian Civil Aviation.

By making more measurements in the field for more days, the success rates of the angles within the path can be improved, therefore it is necessary to infer that: the tests must be performed on a real runway with a drone certified for aviation applications, the communication between the drone and the designed application should improve the algorithm in the sample capture times, as well as make an adjustment with regard to the selection of the correct data to avoid losses and reduce the deviation because the 
window of work remained between $60.8 \%$ and $95.3 \%$ of the correct data.

The speed and the ascent of the drone is affected by the atmospheric conditions at the time of obtaining the average times of the sample, since, a high variability in the sampling times is observed at the time of selecting the angle more according to the path, as also the generation of null or erroneous data obtained in the field.

Although the calibration and adjustment of lights is still safe through the use of aircraft, it is possible to carry out a complementary implementation with the help of drones, which allows to reduce costs and speed up the transfer of information more precisely with the concept of navigation based on the performance; In addition, with the help of software tools it is safer to activate, deactivate and vary the brightness levels of the lights located on the track and their respective traffic lanes.

Although, drone work is a new alternative as an aid in the calibration of PAPI lights; Colombian Civil Aeronautics and regulators must establish the procedures and measurement standards that allow the use of such technology in the improvement of air safety, and open new research spaces on the subject as part of the new technological trends and calibration equipment in the modernization of national airports.

\section{References}

[1] Organización de Aviación Civil Internacional, "Anexo 14 al Convenio sobre Aviación Civil Internacional", Aeródromos, 2009.

[2] P. Pike, D. L. Ruffini, E. Carome, V. Kubulins and W. Hills, "( 12 ) United States Patent”, vol. 2, no. 12, 2013.

[3] Airports Authority of India, "MANUAL ON AERODROME LICENSING OF AAI AIRPORTS", 2013.

[4] C. C. Ávila Herrera, "Drones vs. Aeronáutica Civil. Licencias para pilotos y su procedimiento", Novum Jus, pp. 135-165, 2017.

[5] Oficina Tecnica de Difusion, "Nota de prensa," Instituto Nacional de Estadistica e Informatica, no. Ldc, pp. 14, 2014.

[6] U. A. Civil Aeronaútical, "Normas de Aeronavegabilidad y Operación de Aeronaves", Reglamentos Aeronáuticos de Colombia, pp. 199-204, 2009.

[7] F. A. A. Airport and E. Division, "EB 95, Additional Siting and Survey Considerations for Precision Approach Path Indictor (PAPI) and Other Visual Glide Slope Indicators (VGSI), December 19, 2017’, pp. 0-11, 2017.

[8] H. Shen, X. Zhou, W. Zhang, J. Pan and M. Liu, "Measurement method for the transition width of precision approach path indicator based on spectral means", vol. 8417, pp. 841743, 2012.

[9] K. M. Gildea, D. L. Perry, C. A. Roberts and L. S. Peterson, "Federal Aviation Administration Usability of Light-Emitting Diodes in Precision Approach Path Indicator Systems by Individuals With Marginal Color Vision", no. may, 2014.

[10] R. Geister, L. Limmer, M. Rippl and T. Dautermann, "Total System Error Performance of Drones for an Unmanned PBN Concept Content - Performance Based Navigation ( PBN ) - PBN for drones Test Setup - Test Results - Conclusion", Integrated Communications, Navigation and Surveillance Conference, no. april, pp. 112, 2018.

[11] H. Kang and and J. Cho, "Case Study on Efficient Android Programming Education using Multi Android Development Tools", Indian Journal of Science and Technology, vol. 8, no. 12, pp. 1-5, 2015.

[12] K. Walpole, R. Myers, R. Myers and S. Ye, "Probabilidad y estadística para ingeniería y ciencias", Norma, 2014.

[13] J. K. Lee, “Android programming techniques 
for improving performance", $3 r d$

International Conference on Awareness Science and Technology, pp. 386-389, 2011.

[14] J. Brandt, P. J. Guo, J. Lewenstein and S. R. Klemmer, "Opportunistic programming: How rapid ideation and prototyping occur in practice", Proceedings of the 4th international workshop on End-user software engineering, pp. 1-5, 2008. 